Uka VK Samson-Akpan PE
Okpara HC
Ekanem EE

DOI:http://dx.doi.org/10.4314/njp.v45i3.2

Accepted: 25th June 2018

Ekanem EE ( $\boldsymbol{\nabla}$ )

Department of Paediatrics,

University of Calabar, Calabar,

Nigeria

Email: profekanem@gmail.com

Uka VK, Samson-Akpan PE

Department of Nursing Science,

University of Calabar, Calabar,

Nigeria

Okpara HC

Department of Chemical Pathology, University of Calabar, Calabar, Nigeria

\section{CC-BY Pre-presentation management, metabolic state and outcome of children admitted for diarrhoea disease in Calabar, Nigeria}

\begin{abstract}
Background: Much of the activities for the prevention and management of diarrhoea should occur or be initiated at home. In addition, management is guided by clinical and metabolic state. This work was designed to examine some prehospital management practices and the metabolic state of children with diarrhoea in Calabar, Nigeria.

Methodology: Prospective study of the pre-presentation management, clinical and metabolic states of children with diarrhoea presenting at University of Calabar Teaching Hospital, Calabar from April to November 2016. History was used to determine prepresentation management while blood glucose and electrolytes were determined before initiation of treatment.

Results: Forty-four children aged 4 - 13years, mean $18.65 \pm$ 17.37 months were recruited into the study. Forty $(90.91 \%)$ had acute watery diarrhoea and 4 $(9.09 \%)$ had dysentery. Of these,

$72.27 \%$ had oral electrolyte solu-
\end{abstract}

tions at home and nine $(20.45 \%)$ zinc. Twelve $(27.27 \%)$ had mild, $26(45.4 \%)$ moderate and 3 $(6.82 \%)$ severe dehydration.

Twenty (63.64\%) had metabolic acidosis, 18(40.91\%) hyponatraemia and $18(40.9 \%)$ azotaemia suggesting Acute Kidney Injury. Two $(4.50 \%)$ had hypoglycaemia while $16(36.30 \%)$ had hypozincaemia. Conclusion: A majority of children with diarrhoea have oral electrolytes solution before presentation in the hospital and all had continued feeding. There is a high proportion with hyponatremia and more than a third hadazotaemia. Modality of treatment at home did not seem to affect these parameters, perhaps because all subjects had continued feeding. Further studies on the appropriateness of low osmolarity ORS in this environment and renal function of children with diarrhoeaare recommended.

Key Word: Diarrhoea, Prehospital Management, electrolytes derangement

\section{Introduction}

While there has been remarkable reduction in diarrhoea morbidity and mortality in recent years, it still causes more than half a million $(525,000)$ under five childhood deaths annually. ${ }^{1-4}$ When diarrhoea occurs good management with the use of appropriate oral rehydration fluids to prevent or correct dehydration, vitamin A, zinc, and continued feeding are essential to lessen morbidity and prevent mortality. ${ }^{3-6}$ Much of these should be done or initiated at home. ${ }^{5}$

Home management of diarrhoea can significantly affect ultimate outcome. Several studies in Africa and other parts of the developed have shown widely different modalities of pre-facility presentation management of diarrhoeal disease in children. In India Ahmed et $\mathrm{al}^{7}$ re-
}

ported in 2009 that only $8.7 \%$ of children received ORS for current episode of diarrhoea and $77.9 \%$ received antibiotics while $4.0 \%$ of parents withheld foods. Othero et $\mathrm{al}^{8}$ in Kenya reported in 2005 that $27.8 \%$ of the children had no fluids at all during diarrhoeal episodes, $70 \%$ of mothers decreased fluid intake and only $10.0 \%$ increased fluid intake. Almost $90 \%$ of the mothers withheld milk, including breast milk. ${ }^{8}$ On the other hand, in Nigeria, Uchendu et $\mathrm{al}^{9}$ in a hospital based study in 2011 reported that $73.1 \%$ of the children with diarrhoea had some form of oral rehydration fluid before presentation at hospital, out of which $80.7 \%$ had (standard) ORS and 94.8\% continued feeds. A recent study in Port Harcourt, Nigeria showed that more than 70 percent presenting with diarrhoea at a cottage hospital had some form of oral rehydration fluid before presentation, with $97.4 \%$ of 
these having standard ORS solution, with a majority $(57.4 \%)$ having antimicrobials while more than a third had anti-emetics. ${ }^{10}$ Thus home/pre-presentation management of childhood appears to vary between and within country, with implications for in-facility management and health education activities.

This work was designed to examine pre-presentation management, metabolic state and outcome of children presenting with diarrhoea at the University of Calabar Teaching Hospital, Calabar, Nigeria.

\section{Materials and Methods}

This was a prospective study of all children admitted into the DTTU of the University of Calabar Teaching Hospital from April to November, 2016. A selfdeveloped questionnaire with four sections covering socio-demographic characteristics of child and mother, pre-presentation management, clinical and metabolic states, and outcome, was used to collect data.The instrument was assessed for face validity with a test-re-test used to ascertain its reliability.

After informed consent of parent/care-giver, history and physical examination with attention to state of hydration was obtained. Three milliliters $(3 \mathrm{ml})$ of venous blood was drawn from each patient; $1.5 \mathrm{ml}$ each was added into a plain bottle and fluoride oxalate bottle. The specimens were taken to the Chemical Pathology Laboratory of the samehospitalwhere they were centrifuged at 3000rpm for 10munites. The supernatant serum (from the plain bottle) for electrolytes and zinc analyses were stored at $20^{\circ} \mathrm{C}$ for a maximum period of two weeks before batch analysis. The supernatant plasma (from the fluoride oxalate bottle) was separated and immediately used for glucose analysis.

The plasma glucose was analyzed using the glucose oxidasephotomeric method produced by Biolabo® (Biolabo SA 02160, maicy France). The serum electrolytes were analyzed using an ion selective electrode (ISE) machine (ISE model unit - 910C, URIT Medical Electronic Co, Ltd, China). The serum zinc analysis was carried out using an atomic absorption spectrophometer (AAS Model 205, Bulk Scientific, United Sates of America).

\section{Data Analysis}

Data was entered into an Excel spreadsheet then transferred to stata 10 (stata Corp Texas) for analysis. Frequencies, simple proportions and percentages were used to analyze the data. Chi-square test was used to test associations.

\section{Ethical Issues}

Ethical clearance for the study was obtained from the Health Research Ethics Committee of the University of Calabar Teaching Hospital, Calabar, with reference number: UCTH/HREC/33/337. Informed consent was obtained from all participating parents/caregivers, with assurance that refusal to participate would not prejudice the care of their children/wards.

\section{Results}

Forty-four children were recruited into the study. The age range was $4-13$ months with a mean age of $18.7 \pm$ 17. 4 months. Twenty four of the children were males and 20 females give a male to female ratio of 1:2:1.

The mean duration of diarrhea before presentation was $3.0 \pm 2.8$ with a range of $2-.4$ days. Forty $(90.9 \%)$ of the children had acute watery diarrhoea while $4(9.1 \%)$ had dysentery. None had persistent diarrhoae. Twenty eight $(63.6 \%)$ had associated vomiting. Twenty six $(45.5 \%)$ of the subjects presented with moderate dehydration. Twelve $(27.3 \%)$ had mild dehydration while 3 (6.8\%) had severe dehydration. Three $(6.8 \%)$ had no signs of dehydration.

\section{Pre-presentation management}

Fifteen $(34.1 \%)$ of the children had exclusive breast feeding in the first six months of life. All the children had continued feeding at home during the episode of diarrhoea.

\section{Fluids}

Thirty-two $(72.3 \%)$ of the children had oral fluids before presentation. Of these $6(13.6 \%)$ had low osmolarity Oral Rehydration Salt Solution (ORS), 17(38.6\%) standard ORS and $9(20.5 \%)$ salt-sugar-solution.

Nine $(20.5 \%)$ had zinc, $13(29.6 \%)$ had anti-microbialsas follows; $8(18.2 \%)$ metronidazole; 2 (4.6\%) cotrimoxazole; $2(4.6 \%)$ cephalosporin and 1(2.3\%) amoxicillin/clavitunate. One $(2.3 \%)$ each had metroclopraimide and "Lucozade"

\section{Clinical state}

Table 1 shows the clinical state of the children in relation to modalities of pre-presentation management. Degree of hydration was not influenced by the administration of zinc nor by the type of oral rehydration fluid used.

\section{Metabolic State}

Table 2 shows the metabolic state of the children on admission. The important abnormalities were metabolic acidosis in 28 or $63.6 \%$ of the children, hypozincaemia (16 or $36.3 \%$ ), raised creatinine (14 or $31.8 \%$ ) hyponatraemia (18 or $40.9 \%$ ) and hypokalaemia (6 or $13.6 \%)$. Two $(4.6 \%)$ of the children had hypoglyceamia. Eighteen $(40.9 \%), 95 \mathrm{Cl} 26.3 \%-56.8 \%$ of the children had azotaemia, (increased urea and/or creatinine). 


\begin{tabular}{|c|c|c|c|c|c|c|}
\hline Metabolite(mmol|L) & Range & Mean & SD & Low & Normal & Elevated \\
\hline $\operatorname{Zinc}(0.06-1.20)$ & $0.0-70$ & 1.14 & 1.35 & $16[36.36]$ & $15[34.09]$ & $13[29.38]$ \\
\hline Sodium $(135-145)$ & $120.7-146.0$ & 135.22 & 6.23 & $18[40.91]$ & $25[36.82]$ & $1[2.27]$ \\
\hline Potassium $(3.5-5.5)$ & $3.0-5.4$ & 4.01 & 0.55 & $6[13.64]$ & $38[86.36]$ & $0[0.00]$ \\
\hline Chloride $(98-106)$ & $840-106.1$ & 98.25 & 5.98 & $15[34.09]$ & $27[61.36]$ & $2[4.5]$ \\
\hline Bicarbonate $(2.00-26.0)-$ & $18.1-26.0$ & 21.46 & 2.35 & $28[63.64]$ & $16[36.36]$ & $0[0.00]$ \\
\hline Urea $(1.8-6.4)$ & $1.8-7.8$ & 4.46 & 1.69 & $3[6.82]$ & $39[77.27]$ & $7[15.91]$ \\
\hline Creatinine $(18.0-35.0)$ & $18-46.2$ & 23.39 & 8.95 & $0[0.00]$ & $30[68.18]$ & $14[31.82]$ \\
\hline Glucose $(3.6-5.8)$ & $1.8-7.9$ & 4.72 & 1.24 & $2[4.55]$ & $42[95.45]$ & $0[0.00]$ \\
\hline
\end{tabular}

Key: $($ ) $=$ Reference values

()$=$ Percentage

\begin{tabular}{|c|c|c|c|c|c|c|}
\hline $\begin{array}{l}\text { Home } \\
\text { Treatment }\end{array}$ & $\begin{array}{l}\text { No } \\
\text { dehy- } \\
\text { dration }\end{array}$ & $\begin{array}{l}\text { Mild } \\
\text { dehy- } \\
\text { dratio } \\
\mathrm{n}\end{array}$ & $\begin{array}{l}\text { Moder- } \\
\text { ate } \\
\text { dehy- } \\
\text { dration }\end{array}$ & $\begin{array}{l}\text { Severe } \\
\text { dehydra- } \\
\text { tion }\end{array}$ & $X^{2}$ & $\mathrm{P}$ \\
\hline No Zinc & 2 & 4 & 15 & 2 & \multirow{3}{*}{0.39} & \multirow[t]{3}{*}{0.94} \\
\hline Zinc & 1 & 4 & 11 & 1 & & \\
\hline SSS & 1 & 1 & 6 & 1 & & \\
\hline Low & 0 & 2 & 2 & 4 & \multirow[t]{3}{*}{2.93} & \multirow[t]{3}{*}{0.18} \\
\hline $\begin{array}{l}\text { os- } \\
\text { molomity } \\
\text { ORS }\end{array}$ & & & & & & \\
\hline $\begin{array}{l}\text { Standard } \\
\text { ORS }\end{array}$ & 1 & 5 & 9 & 2 & & \\
\hline
\end{tabular}

Table 3 shows the metabolic state in relation to type of pre-presentation oral rehydration solution used. Type of home fluid did not affect the distribution of electrolyte changes.

\section{Outcome}

Four $(9.1 \%)$ children had intravenous fluids initially and later low osmolarity ORS. Forty $(90.9 \%)$ had low osmolarity ORS till discharge home.Median duration of stay in the hospital was 24hours (1QR 1-48hours). There was zero case fatality.

\begin{tabular}{lccccc}
\hline \multicolumn{6}{c}{ Table 3: Home Management and Metabolic State } \\
& SSS & LOORS & SORS & X $^{2}$ & P \\
\hline Hyponatraemia & 4 & 2 & 8 & 0.03 & 0.98 \\
Hypokalaemia & 3 & 0 & 2 & 2.89 & 0.24 \\
Hypochloraemia & 3 & 0 & 6 & 1.99 & 0.37 \\
Azotaemia & 4 & 1 & 5 & 0.74 & 0.69 \\
\hline
\end{tabular}

Key

SSS: Salt sugar solution

LOORS: Low osmolarity ORS

SORS: Standard ORS

\section{Discussion}

The age distribution of the children was expected and is in keeping with the known epidemiology of the diarrhoea disease. The slight male preponderance is also typical, so also the preponderance of acute watery diarrhoea. ${ }^{1-3,5}$ Appropriate home management of diarrhoea, including appropriate oral dehydration fluid, continuing feeding, zinc therapy, are important modalities of reducing morbidity and mortality from diarrhoea disease. ${ }^{4,5}$
The low exclusive breastfeeding rate among these children is in keeping with the situation in Nigeria, reported to be the poorest in the world. ${ }^{7-9}$ Gratifyingly, all the subjects continued feeding during the episodes of diarrhoea. This is different from the situation in the past ${ }^{[4]}$ and reflects some gains in the health education on the management of diarrhoea disease at home. More than seventy percent of the children had some form of oral fluid, though the correctness of the constitution was not assessed. This is not satisfactory as all children with diarrhoea should have extra fluids as soon as the diarrhoea starts. ${ }^{4}$ All the children had continued feeding during the episodes of diarrhea. This is most salutary and is much different from the report in India in 2009 where up to four percent had no feeds during diarrhoeal episodes $^{7}$ are in Kenya where about $90 \%$ of the children had milk, or including breast milk withheld in a 2005 report. ${ }^{8}$ This may reflect the high level of maternal education in Cross River state of Nigeria which has adult English language literacy rate for both sexes of more than seventy six percent, ${ }^{11}$ and similar to report in the nearby Enugu state in Nigeria with adult English literacy rate of more than sixty four percent, ${ }^{11}$ and more than seventy three percent of children with diarrhea were offered oral rehydration fluid at home. ${ }^{9}$ Maternal education is known to affect both the incidence and home management of childhood diarrhoea. ${ }^{12,13}$

Only a fifth of the children had zinc. This reflects weak knowledge of this relatively recent recommendation by the pre-presentation care-givers. Zinc supplementation has been demonstrated to reduce the duration of acute diarrhoea; and for persistent diarrhoea duration and the probability of treatment failure or death. ${ }^{14}$ Zinc supplements for 10-14 days during diarrhoeal episode has also been shown to reduce further occurrences in the subsequent 2-3 months ${ }^{14}$ and is currently recommended as a routine. ${ }^{15}$ Mechanism of action of zinc is not fully understood but includes improvement of water and electrolytes absorption, regeneration of intestinal epithelium, increase in the level of brush boarder enzymes and enhancement of immune response against the diarrhoea pathogens. ${ }^{14}$ The rate of antimicrobial use in the present study was $18.2 \%$ though only $4(9.1 \%$ ) had dysentery. This is a lot better than the situation in Kashmir, India where the rate of antibiotic use was close to $78 \%{ }^{7}$ and in Port Harcourt, Nigeria where nearly sixty percent had antimicrobials. ${ }^{10}$ Only one child had anti-emetic in the current study. This again may reflect the high maternal literacy rate in the area and is markedly different from the report from Port Harcourt where more than a third of the children had antiemetic is ${ }^{10}$ with dire consequences 
for some. ${ }^{10,16}$

While only nine percent had dysentery, thirteen percent had antimicrobials. Abuse of anti-microbials and antiemetics in children with diarrhoea is a well-known phenomenon in Nigeria. ${ }^{10}$ Fortunately only one child had an anti-emetic.

The low incidence $(4.5 \%)$ of hypoglycaemia in these children is almost identical to the $4.0 \%$ recorded in the same unit a few years earlier ${ }^{17}$ and is much lower than the 11.0 percent reported by Huq et $\mathrm{al}^{18}$ in Bangladesh and 7.7 percent by Onyiriuka et $\mathrm{al}^{19}$ in Benin city, Nigeria and the $5.3 \%$ in Lagos, Nigeria by Oyenusi et al. ${ }^{20}$ This may reflect the continued feeding of all the children in the current study. The single child with hypoglycaemia had an anti-emetic. Anti-emetics have been associated with hypoglycaemia in childhood diarrhoae. ${ }^{16}$ Perhaps children with diarrhoea and history of initiation of anti-emetics, which interferes with feeding, should be screened for hypoglycaemia.

Forty percent of the children were hyponatraemic. However, their electrolyte levels were not re-assessed after rehydration. It would be needful to assess the electrolyte and osmolarity changes of children in response to low osmolarity ORS in this environment in view of the high proportion of them with hyponatraemia. While low osmolarity ORS has been demonstrated to be associated with less vomiting and lower stool volume in children admitted with diarrhoea and is currently the recommended fluid by $\mathrm{WHO},{ }^{21}$ it has also been associated with increased incidence of transient asymptomatic hyponatraemia. ${ }^{22}$ A little above a tenth of the children had metabolic acidosis which is eminently correctable by standard or low osmolarity ORS. ${ }^{4,5}$ The modality of prepresentation management did not appear to affect the distribution of electrolyte changes in these children. This may reflect the effect of continued feeding during the diarrhoeal episodes and should be encouraged. The large proportion (more than a third) of the children with hypozincaemia in this study indicates that zinc deficiency and diarrhoea may be components of a vicious cycle. Diarrhoea management is therefore a useful entry point for the management of the widespread zinc deficiency in children reported in this environment. ${ }^{23,24}$ Medicine vendors/patent medicine dealers play important roles in the management of childhood diarrhoeal disease in Nigeria. $^{25,26}$ These should receive targeted education on the use of zinc and other aspects of diarrhoeal management.

The relatively high incidence of azotaemia in this study, probably occurring as a result of pre-renal AKI, is noteworthy. Reversible acute kidney injury occurring in hospital has been shown to be associated with a significant risk for de novo chronic kidney disease, with implications for long term follow up of such patients. ${ }^{27}$ Acute Kidney Injury and Chronic Kidney Disease (CKD), have been considered a continuous spectrum with vascular insufficiency, cell-cycle disruption and maladaptive repair mechanism as some of the modulators of progression from AKI to CKD. ${ }^{28}$ This warrants long-term follow-up of patients with first episodes of AKI, even if they presented with normal renal function. ${ }^{28}$ Since AKI and CKD are currently considered inter-connected syndromes, ${ }^{29-30}$ it would be desirable to investigate the incidence of AKI in children with diarrhoea and establish the need and modalities to follow up these children.

Diarrhoea may be playing important role in the pathogenesis of CKD in this environment.

\section{Conclusion}

Acute watery diarrhoea is the main type of diarrhoea presenting in this centre, accounting for more than ninety percent of the cases. Most of the children had moderate dehydration. EBF rate is low among these children and all had continued feeding during diarrhoea while almost three quarters had some form of oral rehydration fluids before presentation. There was significant rate of abuse of anti-microbials. A large proportion were hyponatraemic on admission, indicating a need to investigate the appropriateness of low osmolarity ORS in children with diarrhoea in this environment. More than a third were zinc deficient. There is a high incidence of azotaemia suggesting AKI in these children. This has implications for the future development of CKD and the need for long term follow-up of these children. Larger studies to evaluate the suitability of low osmolarity ORS in this environment AKI, in diarrhoea are warranted. Health education on home management of diarrhoea in Calabar should emphasize zinc supplementation.

This study has some obvious limitations. The sample size is small and details of the mixing of ORS solutions were not obtained. All the same, it has made important observations and raised important questions.

\begin{tabular}{|l|}
\hline Conflict of Interest: None \\
Funding: University of Calabar Senater Grant \\
No.TETFUND|DESS|UNICAL|CALABAR|RP|VOL.IV \\
$\mid 08$
\end{tabular}

\footnotetext{
Acknowledgements

We are grateful to the parents/guardians that participated with us in the management and study of these children. Thanks also to the Resident Doctors and Nurses in the DDTU for their roles in the management of these children. This study was supported by University of Calabar Senate Grant No.TETFUNDDESS|UNICALCALABAR|RP|VOL.IV| 08
} 


\section{References}

1. Liu L, Johnson HL, Consens S, Perin J, Scott S, Lawn JE. Child Health Epidemiology Group of WHO and UNICVEF. Global, Regional and National causes of child mortality; an update systematic analysis for 2010with time trends since 2000 Lancet 2013; 379: $2151-61$

2. WHO Diarrhoeal disease http:// www, who.int/mediacentre/ factsheets/fs330/en/

3. CDC. Global water sanitation, and Hygiene (WASH). Global Diarrhoea Burden. https:// www.cdc.gov/healthywater/ global/diarrhea-burden.html

4. WHO Diarrheal disease fact sheet N0 330. April 2013. http://www.who.int/ mediacentre/factsheet/fs330/en/

5. UNICEF/WHO. Readings on Diarrhea Student Manual. WHO/UNICEF. (undated)

6. Perkin RM. Paediatric hospital; Medicine Textbook of Inpatient Management ( $2^{\text {nd }}$ edition) Philadelphia: Wolter Kluwer Health/Lippin colt Wilkins and Wilkins. 2008; 105 -

7. Fayaz A, Aesha F, Imtiyaz A, Thakur M, Muzaffar A, Samina M. Management of diarrhea in under-fives at home and health facilities in Kashmir. Int $J$ health Sci (Qassim) 2009; 3: 171-175.

8. Doreen MO, Alloys SSO, Ted G, Dan OK, Otengah PA. Home management of diarrhea among underfives in a rural community in Kenya: Household perceptions and practices. East African J. Public Health, 2008; 5(3): 142-146.

9. Uchendu UO, Emodi IJ, Ikefuna AN. Pre-hospital management of diarrhea among caregivers presenting at a tertiary health institution: implications for practice and health education. Afr health Sci 2011; 11 (1): $41-47$
10. Ekanem EE, Fajola AO, Umejiego CN, Ikeagwu GO, Anidima TE. Risk factors, prepresentation management and clinical state of children with diarrhea presenting in a community cottage hospital. Niger J Paediatr 2017; 44(3): 76-80.

11. National Bureau of Statistics. (Nigeria)/National Bureau for mass education/MMCC Group. The National Literacy Survey June, 2010 www.nigeriastat.gov.ng. Accessed 31-5-18.

12. Woldu W, Bitew BD, Gizaw Z Socioeconomic factors associated with diarrhoeal diseases among under-five of the nomadic population in northeast Ethopia. Trop Med Health (Internet) 2016; 44: 40

13. Arif A, Cantt W, Naheed R. Socioeconomic determinants of diarrhoea morbidity. Acad Res Int 2012; 2: 490-518.

14. Bajait C, Thawani V. Role of zinc in Paediatric diarrhoea. Ind J Pharmacol 2011; 43: 232 -235 .

15. WHO. Zinc supplementation in management of diarrhoea. www.who.int. Accessed 1-618.

16. Ekanem EE, Fajola AO. Are we losing the gains of the rehydration strategy: an illustrative case. Nig J Paediatr 2016; 43 : 102-103.

17. Ntia HN, Anah NV, Udo JJ, Ewa AV. Prevalence of hypoglycaemia in under-five children presenting with acute diarrhoae in University of Calabar Teaching Hospital, Calabar. Nig J Paediatr 2012; 39: 63 66.

18. Huq S, hossain MI, Malek MA, Faruque ASG, Salam MA. Hypoglycaemia in under-five children with diarrhoea. J Trop Paed 2007; 53: 197-201.

19. Onyiriuka AN, Awache PO, Kouyate M. Hypoglycaemia at point of hospital admission of under-five children with acute diarrhoea: prevalence and risk factors. Niger J paed 2013; 40: 384-388.
20. Oyenusi EE, Oduwole AO, Oladipo OO, Njokanma OF, Esezobor CI. Hypoglycaemia in children aged 1 month to 10 years admitted to the children's emergency centre of Lagos. S Afr J Child Health 2014; 8: 107-111

21. WHO New oral rehydration salts WHO drug information 2002; 16: 121-122.

22. Habu S, Kin Y, Garner P. Reduced osmolarity oral rehydration solution for treating dehydration coursed by acute diarrhea in children. Cochrone Database of systemic Review 2002, Issue 1. Art No: CD 002 \& 47 Dol:10:1002/14651858. CD 002847.

www.cochronelibrary.com

23. Ibeawuchi ANE, Onyirivka AN, Adiodon PO. High prevalence of zinc deficiency in normal Nigeria pre-school children: a community based cross-sectional study. J Ron Soc Diab Nutr Metab Dis 2017; 24: 31 - 39.

24. Nnam N, Steve-Edemsa C. Vitamin A and zinc status of children $60 \%-0$ - 5 years living in ten orphanages in Abuja Nigeria. EJNFS. 2015; 112: $454-$

25. Aguwa EN, Aledue PN, Obi IE. Management of children diarrhea by patent medicine vendors in Enugu Local Government Arears, South Eastern Nigeria. Int Med Med Scs 2010; 2: 88-93.

26. Uzochukwu BSC, Onyujekwe OE, Okwosa C, Ibe PO. Patent Medicine dealers and initial use of medicines in children: the economic cost implications for reducing children mortality in south east Nigeria. Plus ONE - 9(3): e91667 do: 1371/journal.

27. Bucaloiu ID, Kirchaer HL, Norfolk ER, Hartle JE, Perkins RM. Increased risk of death and de novo chronic kidney disease following reversible acute kidney injury. Kidney International 2012; 81: 477 - 485 
28. Chawla LS, Kimmel PL. Acute Kidney Injury and chronic kidney disease; an integrated clinical syndrome. Kidney International 2012; 82: 516- 24.
29. Coca SG, singanamala 5, Parikh CR, Chronic kidney disease after acute kidney injury a systemic review and meta-analysis. Kidney International 2012; 81: 442-448.
30. Lee SY. Acute Kidney injury and chronic kidney disease as interconnected syndromes. Korean J Med 2015; 88:382 386. 